\title{
Lymphovascular invasion and histologic grade are associated with specific genomic profiles in invasive carcinomas of the breast
}

\author{
Felipe Fidalgo • Tatiane Cristina Rodrigues • Mabel Pinilla • Amanda Gonçalves Silva • \\ Maria do Socorro Maciel • Carla Rosenberg • Victor Piana de Andrade • \\ Dirce Maria Carraro • Ana Cristina Victorino Krepischi
}

Received: 27 June 2014 / Accepted: 29 October 2014 / Published online: 13 November 2014

(C) The Author(s) 2014. This article is published with open access at Springerlink.com

\begin{abstract}
Lymphovascular invasion (LVI) and histologic grade are clinical parameters of high prognostic value in breast cancer and indicate the level of tumor aggressiveness. Many studies have focused on the association of breast cancer subtypes with gene expression and chromosomal profiles, but considerably less genomic information is available regarding traditional prognostic factors such as histologic grade and LVI. We studied by array-CGH a group of 57 invasive ductal carcinomas of the breast to outline the DNA copy number aberration (CNA) profile linked to high histologic grades and LVI. Selected CNAs were validated using real-time quantitative PCR (qPCR). Furthermore, gene expression analysis was performed in a subset of 32 of these tumors, and findings were integrated with array-CGH data. Our findings indicated an accumulation of genomic alterations in high-grade breast tumors compared to low-grade samples. Grade III tumors showed higher number of CNAs and larger aberrations than low-grade tumors and displayed a wide range of chromosomal
\end{abstract}

Electronic supplementary material The online version of this article (doi:10.1007/s13277-014-2786-z) contains supplementary material, which is available to authorized users.

F. Fidalgo $\cdot$ M. Pinilla $\cdot$ D. M. Carraro • A. C. V. Krepischi International Research Center, AC Camargo Cancer Center, São Paulo, Brazil

T. C. Rodrigues $\cdot$ A. G. Silva $\cdot$ C. Rosenberg $\cdot$

A. C. V. Krepischi $(\bowtie)$

Department of Genetics and Evolutionary Biology, Institute of

Biosciences, University of São Paulo, São Paulo, Brazil

e-mail: ana.krepischi@ib.usp.br

M. Maciel

Department of Breast Cancer, AC Camargo Cancer Center, São Paulo, Brazil

V. P. de Andrade

Department of Surgical and Investigative Pathology, AC Camargo Cancer Center, São Paulo, Brazil aberrations, which were mainly 5p, 8q, 10p, 17q12, and 19 gains, and 3p, 4, 5q proximal, 9p, 11p, 18q, and 21 losses. The presence of LVI, a well-established prognostic marker, was not significantly associated with increased genomic instability in comparison to breast tumors negative for LVI, considering the total number of chromosomal alterations. However, a slightly increase in the frequency of specific alterations could be detected in LVI-positive group, such as gains at $5 \mathrm{p}, 16 \mathrm{p}$, $17 \mathrm{q} 12$, and 19 , and losses at $8 \mathrm{p}, 11 \mathrm{q}, 18 \mathrm{q}$, and 21 . Three newly reported small-scale rearrangements were detected in high-risk tumors (LVI-positive grade III) harboring putative breast cancer genes (amplicons at 4q13.3 and 11p11.2, and a deletion at 12p12.3). Furthermore, gene expression analysis uncovered networks highlighting S100A8, MMP1, and MEDI as promising candidate genes involved in high-grade and LVIpositive tumors. In summary, a group of genomic regions could be associated with high-risk tumors, and expression analysis pinpointed candidate genes deserving further investigation. The data has shed some light on the molecular players involved in two highly relevant prognostic factors and may further add to the understanding of the mechanisms of breast cancer aggressiveness.

Keywords Invasive ductal carcinomas of the breast - Breast cancer - DNA copy number aberrations · CNA . Lymphovascular invasion · Histologic grade III · Gene expression $\cdot$ S100A8 $\cdot M M P 1 \cdot M E D 1 \cdot A D A M T S 3$. HSD $17 B 12$

\section{Introduction}

Breast cancer is a significant cause of cancer-related death worldwide [1]. Despite significant advances in diagnosis and treatment, several considerable clinical and scientific problems remain unresolved. Invasive ductal carcinomas (IDC) 
of no special type (NST) represent $80 \%$ of all invasive tumors of the breast. IDC can be associated with a poorer prognosis than certain special types of breast cancer (such as tubular and mucinous carcinomas) and shows significant biological heterogeneity. Traditional variables, such as tumor size, axillary nodal status, histologic grade, and lymphovascular invasion (LVI) status, are part of risk assessment and deliver significant prognostic information, albeit with limited predictive value [2-6].

The histologic grade [Scarff-Bloom-Richardson (SBR)] modified by Elston and Ellis (modified SBR or Nottingham system) is a widely validated prognostic factor recommended by the Union for International Cancer Control (UICC, 2009). This index grades phenotypic aggressiveness according to morphological criteria based on tubular formation, nuclear pleomorphism, and mitotic counting [7]. Although many studies have focused on the association of breast cancer subtypes with gene expression and chromosomal profiles, considerably less genomic information is available regarding traditional prognostic factors such as histologic grade and LVI [8-12].

Recent studies point to the significance of DNA copy number aberrations (CNAs) in the etiology of cancer with the number and complexity of these aberrations being indicative of overall prognosis [10, 13-15]. CNA investigation may assist the identification of regions containing oncogenes and tumor suppressor genes [16]. Grade III breast tumors frequently harbor gains at $3 q$ and $5 p$, and $8 q$ amplifications $[10,11]$. More recently, a 19q12 amplification was detected, primarily associated with grade III breast tumors in estrogennegative samples, which encompasses the CCNE1 gene, among others [17]. Grade I tumors show less complex karyotypes with recurrent gain of $16 \mathrm{p}$, as found in estrogen-positive tumors $[11,18]$. However, to the best of our knowledge, no study has investigated the genomic profile of CNAs related to the presence of LVI in breast carcinomas.

We performed a study outlining the CNA and gene expression patterns of invasive carcinomas of the breast to identify genomic alterations and differentially expressed genes linked to high histologic grades and LVI. We suggest several genes as potential biomarkers of breast cancer aggressiveness with the ultimate goal of improving patient care.

\section{Materials and methods}

Study approval and patient samples

This retrospective study was approved by the local Ethics and Research Committee of A.C. Camargo Cancer Center, São Paulo, Brazil (\#1448/10), and informed consents were obtained from all patients. Frozen samples from 57 invasive ductal carcinomas of the breast were retrieved from the A.C.
Camargo Cancer Center Biobank for DNA and RNA extractions. All selected carcinomas were tested for estrogen receptor, progesterone receptor, and HER2 status, and analyses followed the ASCO/CAP guidelines [19, 20]. Detailed clinical characteristics of the 57 breast carcinomas are given in Supplementary Table S1. These tumors were selected because of their availability as frozen samples.

\section{DNA and RNA isolation}

Genomic DNA was extracted according to the procedure of the Biobank of the institution [21]. Sample quality and quantity were assessed using NanoDrop (Thermo Scientific, Waltham, MA, USA), and molecular weight was checked by electrophoresis in agarose gels. RNA was obtained from epithelial cells from invasive ductal carcinomas samples captured by laser microdissection using the PixCell II LCM system (Arcturus Engineering, Mountain View, CA, USA). Only RNA samples with optical density of approximately 2.0 and RNA integrity number $>5.0$ were used for microarray experiments [22].

Comparative genome hybridization based on microarrays

We performed comparative genomic hybridization based on microarrays (array-CGH) in a commercial whole-genome $60 \mathrm{~K}$ platform containing 60,000 oligonucleotide probes (Agilent Technologies, Santa Clara, CA, USA; design 21924). A commercially available pool of healthy human female DNA (Promega, Madison, WI, USA) was used as the reference DNA. The experimental procedure was performed as recommended by the manufacturer. Scanned images were processed using Feature Extraction Software version 10.7.3.1 (Agilent Technologies). Poor-quality hybridizations (quality control $>0.2$ ) were disregarded [23]. CNAs were identified with Nexus software 7.0 (BioDiscovery, Hawthorne, CA, USA) using the FASST2 segmentation algorithm, which is an approach based on the Hidden-Markov model that uses the $\log _{2}$ ratio values of the probes for CNA calling. We applied the following settings: a minimum of five consecutive affected probes (effective resolution of $\sim 200 \mathrm{~kb}$ for CNA calling), a significance threshold set at $10^{-8}$, and threshold $\log _{2}$ ratio Cy3/Cy5 of 0.3 and 1.4 for gain or high copy gain (named amplicons), respectively, and -0.3 and -1.1 for loss and homozygous loss, respectively. Copy number variants reported in the Database of Genomic Variants (DGV, http:// projects.tcag.ca/variation/), CNAs smaller than $50 \mathrm{~kb}$, and data from the sex chromosomes were excluded. Gene annotation was performed according to the GRCh37 using the University of California Santa Cruz Genome Browser (http://genome.ucsc.edu/cgi-bin/hgGateway). The smallest common regions of recurrent aberrations were obtained by implementing the global frequency statistical approach of the 
Significance Testing for Aberrant Copy Number (STAC) method [24]. The parameters had a minimum differential threshold of $25 \%$ and had $p$ values of $p \leq 0.05$ for LVI and $p \leq 0.01$ for histologic grades. The CNA data of each breast tumor group were evaluated for number, length, and types of CNAs (gains, losses, high copy gains, and homozygous losses), and statistical analyses were performed using GraphPad Prism v5.0 (Mann-Whitney test to compare two unpaired groups and Kruskal-Wallis test to compare three unpaired groups).

Copy number validation by real-time quantitative PCR

Real-time quantitative PCR (real-time qPCR) was performed on three genes (ADAMTS3 F:CGTAGAAAGCCTTTGGG, R:GGTGCATGATGGAACG; HSD17B12 F:CCCTTTAAGCCA TTCCG, R:GCCAATATTCAAACCGAGC, and RERGL F:CCCCACAAAGTTCCTTC, R:CTCATCTGCTCTGAAACT $G G$ ) using the SYBR Green system (Applied Biosystems, Foster City, CA, USA) on a 7500 System apparatus (Applied Biosystems, Foster City, CA, USA) with reference DNA (Promega) for copy number calibration. Values were normalized based on data from the GAPDH (12p13) and P2RX7 (12q24) genes, which were not affected by copy number changes in these groups of tumors. Duplicates were analyzed using the comparative 2- $\Delta \Delta \mathrm{Ct}$ cycle threshold method [25]. Values in the range of $0.8-1.2$ indicate two copies, $<0.6$ indicates copy number loss, and $>1.4$ was considered a gain.

\section{Microarray gene expression analysis}

A subgroup of 32 breast carcinomas was evaluated for gene expression based on cDNA microarrays using a $244 \mathrm{~K}$ custom platform (Agilent Technologies, Santa Clara, CA, USA). Samples were hybridized following the manufacturer's protocol. Scanned images were processed using Feature Extraction Software version 10.7.3.1. The identification of genes differentially expressed was performed using the Agilent GeneSpring GX 12.1 software after subtracting background and filtering features flagged as not positive, not significant, or not uniform in normalization (normalization to the 65th percentile shift per array, median across all samples per transcript). To identify differentially expressed genes, we used the $t$ test (unpaired with $5 \%$ false-discovery ratio correction) considering a fold change of $|2|$ with $p \leq 0.05$. The genes belonging to the PAM50 list [26] were excluded from this analysis since their expression profiles predict intrinsic molecular subtypes of breast cancer and, consequently, could interfere with gene changes differentiating tumors according to histologic grades or lymphovascular invasion status. Ingenuity Pathway Analysis (IPA) software was used for the in silico analysis of the sets of differentially expressed genes. Interaction networks were obtained using a core analysis tool, which considered the Ingenuity Knowledge Base (genes + endogenous chemicals), human species, breast cancer cell lines, and all types of tissues and primary cells. The selected networks generated by the program contained at least $40 \%$ of the set of differentially expressed genes identified in the study.

\section{Results}

Table 1 summarizes the frequencies of the clinical categories in the group of 57 carcinomas of the breast. Of these cases, $21 \%$ were classified as triple-negative (estrogen receptor (ER)-, progesterone receptor (PR)-, and human epidermal growth factor receptor 2 (HER2)-negative tumors) [27]. A total of 2,857 CNAs were identified in all of the breast tumors profiled (mean of $\sim 50$ CNAs per sample). The summary of the CNA results and the full array-CGH data can be found in Supplementary Tables S2 and S3, respectively. A complex pattern of multiple chromosomal gains and losses was identified in all samples, the most frequent being gains of chromosomes 1q, 8q, 16p, and 17q and losses affecting 8p, 9p, 11q, 13q, 16q, and 18q (Fig. 1a).

We performed a statistical comparison between subgroups of breast tumor samples according to the presence of lymph

Table 1 Clinical characteristics of the group of 57 primary invasive ductal carcinomas of non-special type of the breast

\begin{tabular}{llc}
\hline Clinical variable & Category & Number (\%) \\
\hline LVI $^{\mathrm{a}}$ & Positive & $25(43.9)$ \\
& Negative & $32(56.1)$ \\
SBR $^{\mathrm{b}}$ & $\mathrm{I}$ & $9(15.8)$ \\
& II & $17(29.8)$ \\
& III & $31(54.4)$ \\
Clinical stage & I & $9(15.8)$ \\
& II & $21(36.9)$ \\
& III & $26(45.6)$ \\
Axillary lymph node & IV & $1(1.7)$ \\
& N0 & $20(35.1)$ \\
& N1 & $19(33.3)$ \\
Estrogen receptor & N2 & $10(17.5)$ \\
& N3 & $8(14.0)$ \\
ERBB2 & Positive & $33(57.9)$ \\
Triple-negative & Negative & $24(42.1)$ \\
& Positive & $5(8.8)$ \\
& Negative & $52(91.2)$ \\
& Yes & $12(21.0)$ \\
& No & $45(79.0)$ \\
\hline
\end{tabular}

\footnotetext{
${ }^{\mathrm{a}}$ Lymphovascular invasion

${ }^{\mathrm{b}}$ SBR grade, Scarff-Bloom Richardson graduation system (histological grade)
} 


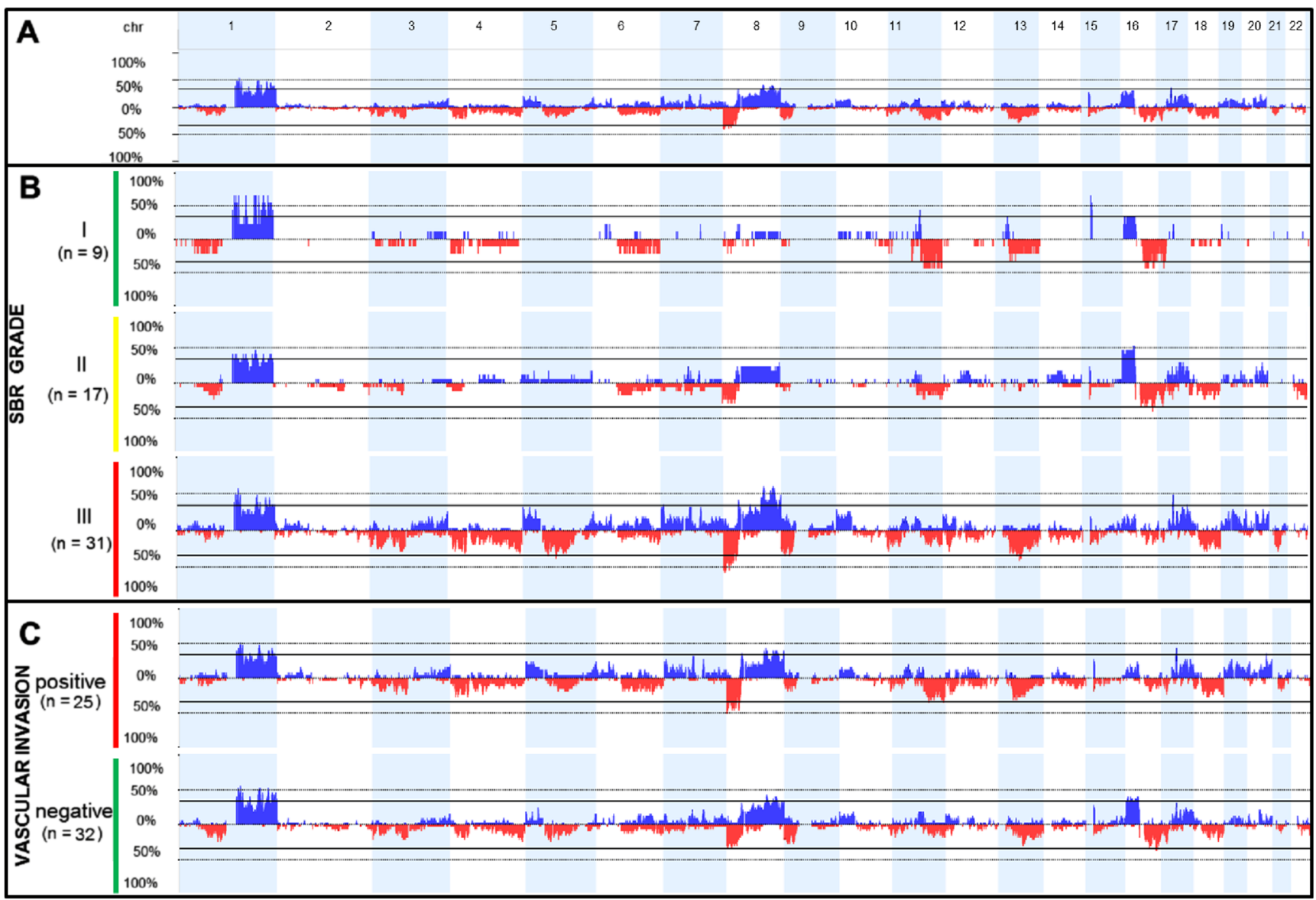

Fig. 1 Array-CGH genomic profile exhibiting the frequency of DNA copy number aberrations (CNAs) in the group of invasive ductal carcinomas of the breast. The $x$-axis represents the genomic positions of chromosomes $1 \mathrm{p}$ to $22 \mathrm{q}$, and the $y$-axis denotes the percentage of gains (plotted in blue above the $0 \%$ baseline) and losses (plotted in red below the $0 \%$ baseline) in all selected samples at the specified genomic location (images adapted from the Nexus Copy Number 7.0 software,

node metastasis: tumors from patients without lymph node metastasis ( $\mathrm{N} 0=20$ samples) and tumors from patients harboring lymph node metastasis at diagnosis. Significant differences were not detected.

Total CNAs and their distribution and type according to histological grade

We compared different tumor subgroups according to histologic grades to assess the total number of CNAs and the CNA distribution with regard to the different types of events (gain, high copy gain, loss, homozygous loss). These results are detailed in Table 2.

Grade III tumors showed a statistically higher total number of CNAs compared to grade I $(p=0.045)$ and grade II $(p=0.006)$ tumors (Mann-Whitney test, Fig. 2a). Additionally, grade III group had a higher number of gains ( $p=0.007$, Fig. $2 b)$ and losses ( $p=0.0148$, Fig. 2c) compared to low-grade tumors (Mann-Whitney test), and the CNAs were larger than those
BioDiscovery). chr indicates the chromosome, and $n$ is the number of samples in each group. a The genomic profile of CNAs (gains and losses) of all 57 invasive ductal carcinomas of the breast. b CNA profile of breast tumors grouped according to histologic grade (I, II, and III). c CNA profile of breast tumors grouped according to lymphovascular invasion status.

detected in the grade II group ( $p=0.0498$, Mann-Whitney test; Fig. 2d).

In a visual inspection, grade III tumors exhibited a wider range of chromosomal aberrations than grades I and II. In particular, CNAs detected preferentially or almost exclusively in this group included the following: gains affecting 5p, 8q, 10p, $17 \mathrm{q} 12$ (ERBB2), and 19 and losses at 3p, 4, 5q proximal, 8p, 9p, 11p, 18q, and 21 (Fig. 1b).

Using the STAC statistical analysis, we detected the smallest common regions of aberrations associated with histologic grade III. Peaks of genomic regions preferentially present in grade III tumors (minimum threshold of $25 \%$ ) were detected in several chromosomes, including peak gains at $5 \mathrm{p} 15,7 \mathrm{p} 22,8 \mathrm{q} 22,8 \mathrm{q} 24,10 \mathrm{p} 12.1,19 \mathrm{q} 12$, and 20p13 and peak losses at 4p13p12, 4q34q35, 9p21, 5q11q23, 12p12, and 21q21 (Supplementary Table S4).

In our samples, the manual curation of CNA data from each tumor sample revealed that the most frequent alteration identified both in grades I (33.3\%) and II (52.9 \%) was a 16 p gain, 
Table 2 Total number of DNA copy number aberrations (CNAs), their distribution in each different CNA class (gain, loss, high copy gain, homozygous loss), and genomic lengths according to histologic grades (SBR) and lymphovascular invasion status (LVI)

\begin{tabular}{|c|c|c|c|c|c|c|}
\hline Group & $\begin{array}{l}\text { Total events } \\
\text { (median) }\end{array}$ & $\begin{array}{l}\text { Gains } \\
\text { (median) }\end{array}$ & $\begin{array}{l}\text { Losses } \\
\text { (median) }\end{array}$ & $\begin{array}{l}\text { High copy gains } \\
\text { (mean) }\end{array}$ & $\begin{array}{l}\text { Homozygous losses } \\
\text { (mean) }\end{array}$ & $\begin{array}{l}\text { Mean size }(\mathrm{Mb}) \\
\text { (median) }\end{array}$ \\
\hline Breast carcinomas $(n=57)$ & $2,857(38.0)$ & $1,477(23.0)$ & $1,245(16.0)$ & $122(2.1)$ & $13(0.2)$ & $70.2(27.3)$ \\
\hline SBR I $(n=9)$ & $290(21.0)$ & $128(12.0)$ & $155(9.0)$ & $7(0.8)$ & $0(0)$ & $10.0(27.0)$ \\
\hline SBR II $(n=17)$ & $606(20.0)$ & $315(10.0)$ & $241(9.0)$ & $44(2.6)$ & $6(0.3)$ & $16.2(26.6)$ \\
\hline SBR III $(n=31)$ & $1,961 *(60.0)$ & $1,034 *(33.0)$ & $849 *(25.0)$ & $71(2.3)$ & $7(0.2)$ & $48.9 *(27.3)$ \\
\hline LVI positive $(n=25)$ & $1,289(38.0)$ & $676(25.0)$ & $558(14.0)$ & $51(2.0)$ & $4(0.2)$ & $33.1(26.6)$ \\
\hline LVI negative ( $n=32$ ) & $1,568(41.5)$ & $801(22.5)$ & $687(17.5)$ & $71(2.2)$ & $9(0.3)$ & $40.0(27.6)$ \\
\hline
\end{tabular}

${ }^{*} p<0.05$ (statistically significant at this level in the comparison between different SBR grades, Mann-Whitney test)

which was detected only in $15.2 \%$ of the grade III samples (Fig. 1b, Supplementary Table S4). All breast tumors harboring the $16 \mathrm{p}$ gain were found to be positive for estrogen receptor.

Total CNAs and their distribution and type according to LVI status

We also compared the CNA profile of breast tumors according to LVI status and the results are summarized in Table 2. We did not detect statistically significant differences between LVIpositive and LVI-negative groups ( $p$ value $>0.5$ in all comparisons) regarding the total number of CNAs, the CNA distribution (number of gain, high copy gain, loss, homozygous loss), and genomic sizes.

Although we did not detect evidence of an increased genomic instability in LVI-positive breast tumors, some specific rearrangements could be detected at a slightly higher frequency in this group compared to the LVI-negative group, such as gains at 5p, 17q12 (ERBB2), and 19, and losses affecting 8p, $11 \mathrm{q}, 18 \mathrm{q}$, and 21 (Fig. 1c).

Using the STAC analysis, we detected more frequently associated with LVI (minimum of $25 \%$ of the samples) two deletions peaks at 11q24.1 and 11q24.3, encompassing the
Fig. 2 Statistical analysis comparing the DNA copy number aberration (CNA) events between different breast carcinoma groups according to histologic grades. Asterisks indicate statistical significance. a Bar graph of the total number of CNAs showing significant differences between tumor grades I and II compared to grade III. b Bar graph of the number of gain events showing significant differences between tumor grades I and II compared to grade III. c Bar graph of the number of loss events showing significant differences between tumor grades II compared to grade III. d $\mathrm{Bar}$ graph of the genomic alteration sizes of breast tumors showing significant differences between grade II tumors compared to grade III
A

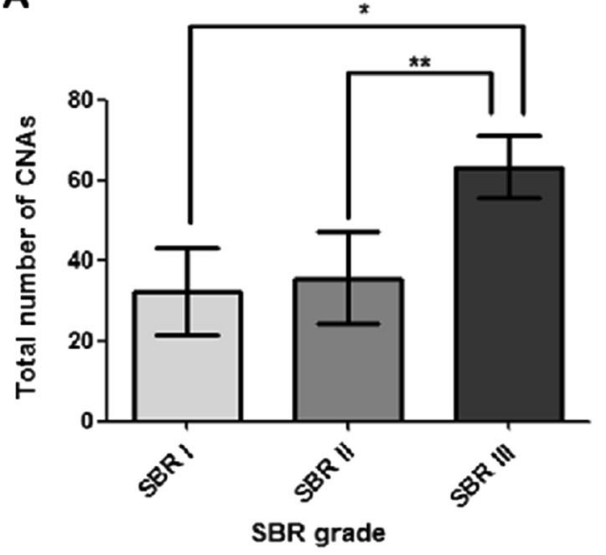

C

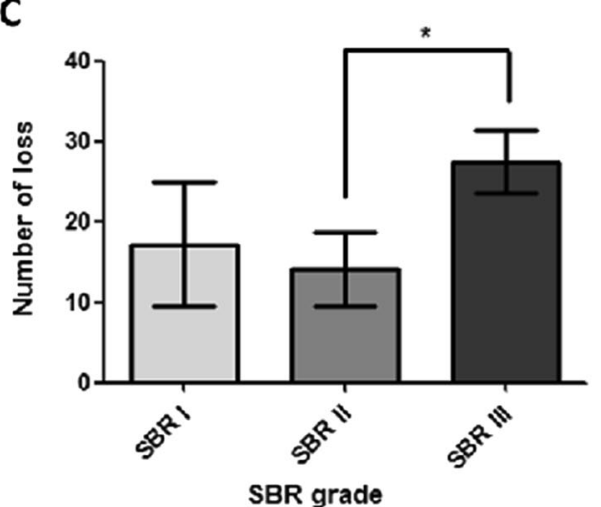

B

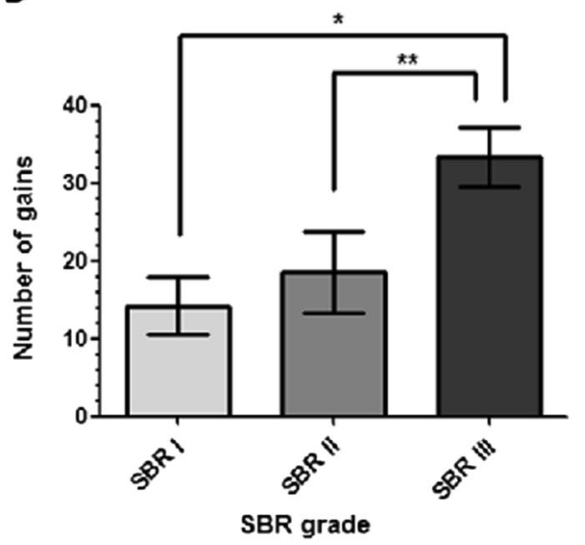

D

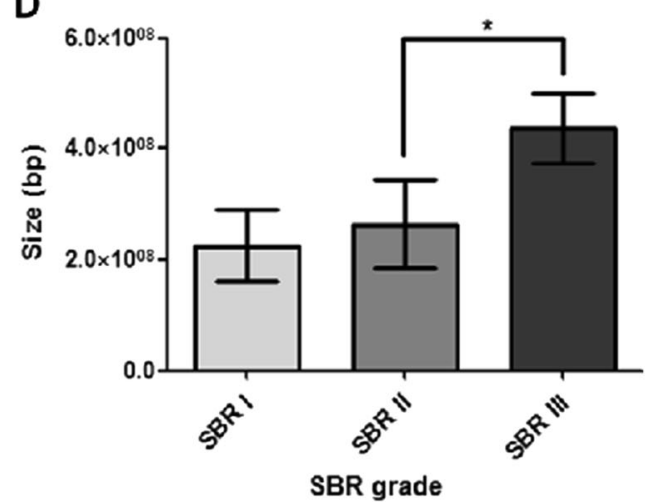


OR6M1 and ARHGAP32 genes, respectively, whereas the $16 \mathrm{p}$ gain and a 16q23 loss were detected at a higher frequency in tumors without LVI (Supplementary Table S5). In fact, the manual curation of CNA data from each tumor sample revealed that the $16 \mathrm{p}$ gain could be detected in about $40 \%$ of the LVI-negative group compared to $24 \%$ of cases presenting LVI. Considering that all these breast tumor samples carrying $16 \mathrm{p}$ gains were found to be positive for estrogen receptor, we performed a statistical correction (logic regression) which showed that the $16 \mathrm{p}$ gain is a marker independently associated with LVI-negative status.

Small-scale rearrangements: genomic amplifications and homozygous losses

We investigated the frequency of six known breast cancer amplicons [28] excluding 17q12 (ERBB2), and all of them were frequently detected in grade III tumors as genomic gains (Table 3). The 19q12 gain was detected exclusively in grade III tumors (one amplification and nine copy number gains), all of them negative for estrogen receptor. The smallest common region affected by this $19 \mathrm{q} 12$ gain was restricted to a $\sim 537 \mathrm{~kb}$ segment at chr19:29,777,917-30,315,215 (GRCh37) in which only six genes are mapped, including CCNE1. Regarding the LVI status, the majority of the tumors carrying the $20 \mathrm{q} 13.2$ gain $(62.5 \%)$ were positive for LVI.

In addition to the abovementioned known breast cancer amplicons, we detected three small-scale rearrangements $(<4 \mathrm{Mb})$ not previously reported, each of them in a different high-risk tumor (grade III positive for LVI): two amplifications, one at 4q13.3 (chr4:72,209,104-73,455,050) and the other at 11p11.2 (chr11:43,830,876-46,190,463); and one homozygous deletion at 12p12.3 (chr12:17,950,780$20,811,443)$. Genes mapped within the two amplified regions were selected for further copy number validation (Supplementary Figure S1). Figure 3 displays the homozygous 12p12.3 deletion encompassing the RERGL and PIK3C2G genes, among others.
The $11 \mathrm{p} 11.2$ genomic amplification encompasses, among others, the $H S D 17 B 12$ gene. In our cohort, we detected $H S D 17 B 12$ gains in association with gains of the $C O X 2$ gene, in a possible 1q31/11p11 co-amplification pattern, here observed in ER-negative high-grade breast tumors.

Copy number status of previously reported breast cancer driver genes

We scrutinized the copy number status of 33 driver cancer genes reported as recurrently affected by copy number changes in breast cancer [11, 17, 29-32], which includes the major genes of the aforementioned amplicons. We also examined the copy number status of three genes highlighted in the present study (ADAMTS3, HSD17B12, and RERGL). Different CNA frequencies affecting these genes were observed according to histologic grade and LVI status (Fig. 4). A panel of 16 genes exhibited copy number changes at higher frequencies in highgrade tumors compared to low-grade samples (losses affecting PPP2R2A, CDKN2A, MTAP, RERGL, RB1, PTEN, INPP4B and gains of CCNE1, ERBB2, EGFR, FGFR1, GATA3, MYC, HSD17B12, ZNF703, and ZNF217; Fig. 4a); conversely, copy number losses of TP53, CDH1, and NCOR1 were detected preferentially in low-grade breast tumors. Furthermore, $E R B B 2$ gains and RERGL losses were more frequent in the presence of LVI (Fig. 4b).

\section{Gene expression profiling}

Table 4 displays the top differentially expressed genes of the breast tumor groups with their respective fold-change values (full differential expression analysis can be found in Supplementary Tables S6 and S7). Histological grade III tumors exhibited 12 up- and 13 downregulated genes compared to low-grade tumors ( $p$ value $<0.001$ and fold change of $|5|$ ). We investigated the copy number status of the detected deregulated genes. The following five genes displayed a CNA pattern concordant with the expression level in $>15 \%$ of the grade III tumors: S100A8 and

Table 3 Frequency of gains affecting well-known breast cancer amplicons in high-risk breast carcinomas (histologic grade III and lymphovascular invasion positive)

\begin{tabular}{lllll}
\hline $\begin{array}{l}\text { Known } \\
\text { amplicon }\end{array}$ & Major gene & $\begin{array}{l}\text { Total frequency }(n \\
\text { affected })\end{array}$ & $\begin{array}{l}\text { Frequency among histologic grade III } \\
\text { samples }\end{array}$ & $\begin{array}{l}\text { Frequency among lymphovascular invasion positive } \\
\text { samples }\end{array}$ \\
\hline $8 \mathrm{q} 24$ & MYC & $38.6 \%(22)$ & $\mathbf{8 1 . 8} \%$ & $45.4 \%$ \\
$8 \mathrm{p} 12$ & ZNF703/ & $31.6 \%(18)$ & $\mathbf{7 2 . 2} \%$ & 44.4 \\
$8 \mathrm{p} 12$ & $F G R 1$ & & $\mathbf{6 4 . 7} \%$ & $47.1 \%$ \\
$19 \mathrm{q} 12$ & FGFR1 & $29.8 \%(17)$ & $\mathbf{1 0 0} \%$ & $\mathbf{5 5 . 5} \%$ \\
$20 \mathrm{q} 13.2$ & CCNE1 & $17.5 \%(10)$ & $\mathbf{6 2 . 5} \%$ & $\mathbf{6 2 . 5} \%$ \\
$11 \mathrm{q} 13$ & ZNF217 & $14.0 \%(8)$ & $\mathbf{5 0 . 0} \%$ & $25.0 \%$ \\
\hline
\end{tabular}

In bold are indicated amplicons that were frequently detected $(\geq 50 \%)$ in tumors of each category 

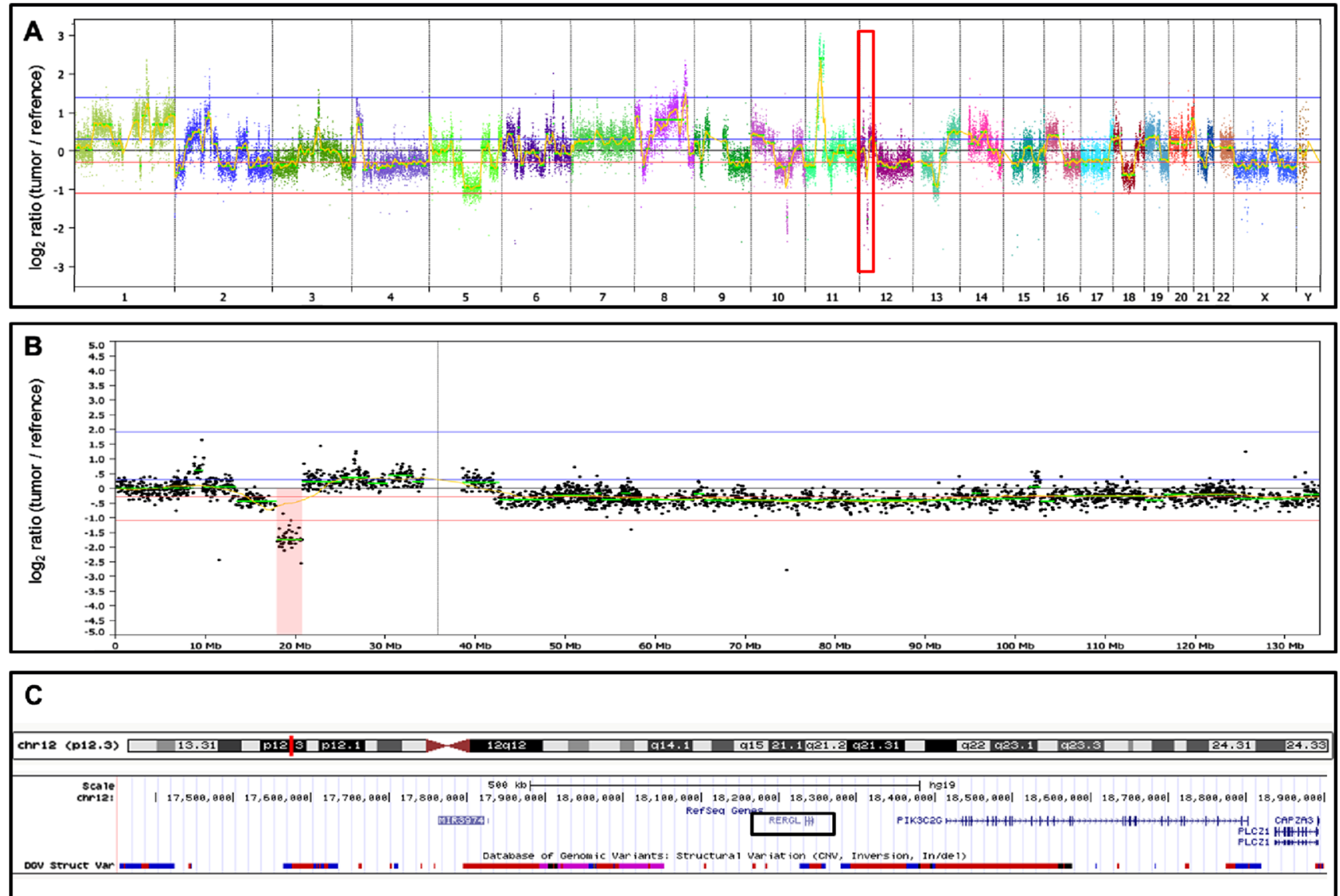

Fig. 3 Homozygous deletion affecting a $1.5 \mathrm{Mb}$ genomic region at 12 p13.3, detected in a high-risk breast tumor (histologic grade III with lymphovascular invasion, MIC82). a Array-CGH genomic profile of the breast carcinoma -the deletion at chromosome 12 is indicated by a red box. b Array-CGH profile of chromosome 12, highlighting the $\sim 1.5 \mathrm{Mb}$ deletion at 12p13.3 (in red). $\mathbf{c}$ The affected genomic segment at 12p13.3 is depicted by the UCSC Genome Browser; this region encompasses five genes, including RERGL (marked by a black box) and PIK3C2G
$M C M 10$ genes (upregulated) and GRP, CX3CR1, and FAM198B (downregulated). We used the network analysis tool of IPA software to reveal regulatory interconnections among these genes. The network with the highest score (26) connected 12 of the deregulated genes with 23 additional ones, showing an enrichment of the categories of Cellular Movement, Hematological System Development and Function, Immune Cell Trafficking (Fig. 5), in which the $S 100 A 8$ gene plays a central role.

Breast tumors with LVI exhibited 11 upregulated and 11 downregulated genes compared to negative tumors ( $p$ value $<0.05$ and fold change of $|2.5|)$. The following four upregulated genes exhibited a concordant CNA pattern in tumors with LVI: $U M O D$ (gains) and $A R S G, M Y C B P A P$, and MEDI (gains and high-copy gains). The 22 deregulated genes were evaluated using the network analysis tool of IPA software. The more relevant network (score 12) connected seven of the differentially expressed genes with additional 28 genes, which showed an enrichment of the categories of Cellular Development, Cellular Growth and Proliferation, Hematological
System Development and Function. In this network, the MED1 gene appears to play a central role (Supplementary Figure S2).

Summary of the relevant genomic regions and selected genes

Table 5 presents a summary of the relevant genomic regions and genes revealed in this work in association either with histologic grade III tumors or with LVI. Data include some of the significant recurrent CNAs, highlighting relevant gene content, as well as three newly detected small-scale rearrangements, and differentially expressed genes possibly deregulated by copy number changes.

\section{Discussion}

Increased numbers of CNAs are expected to be associated with tumor aggressiveness [12]; accordingly, we detected a 


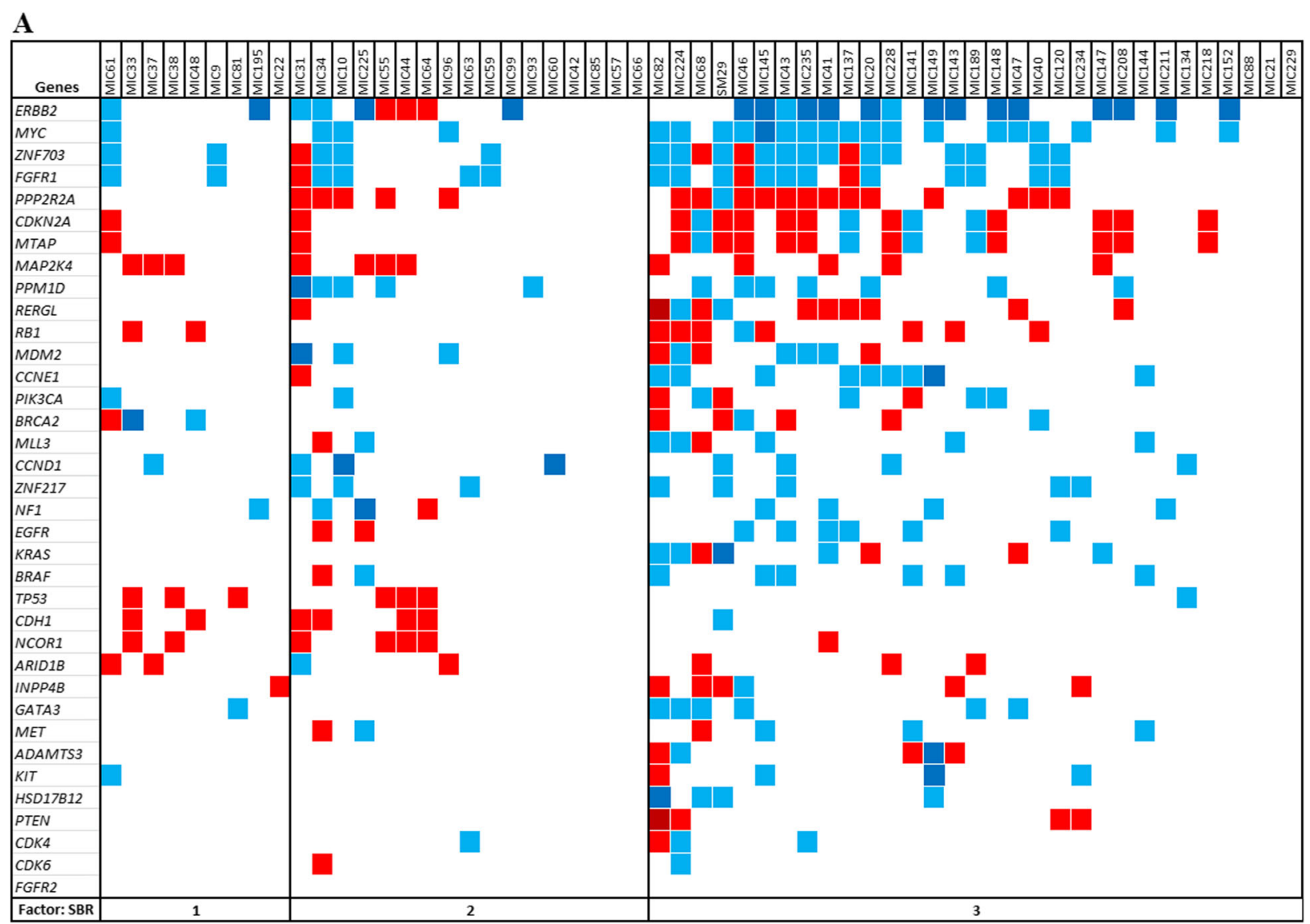

B

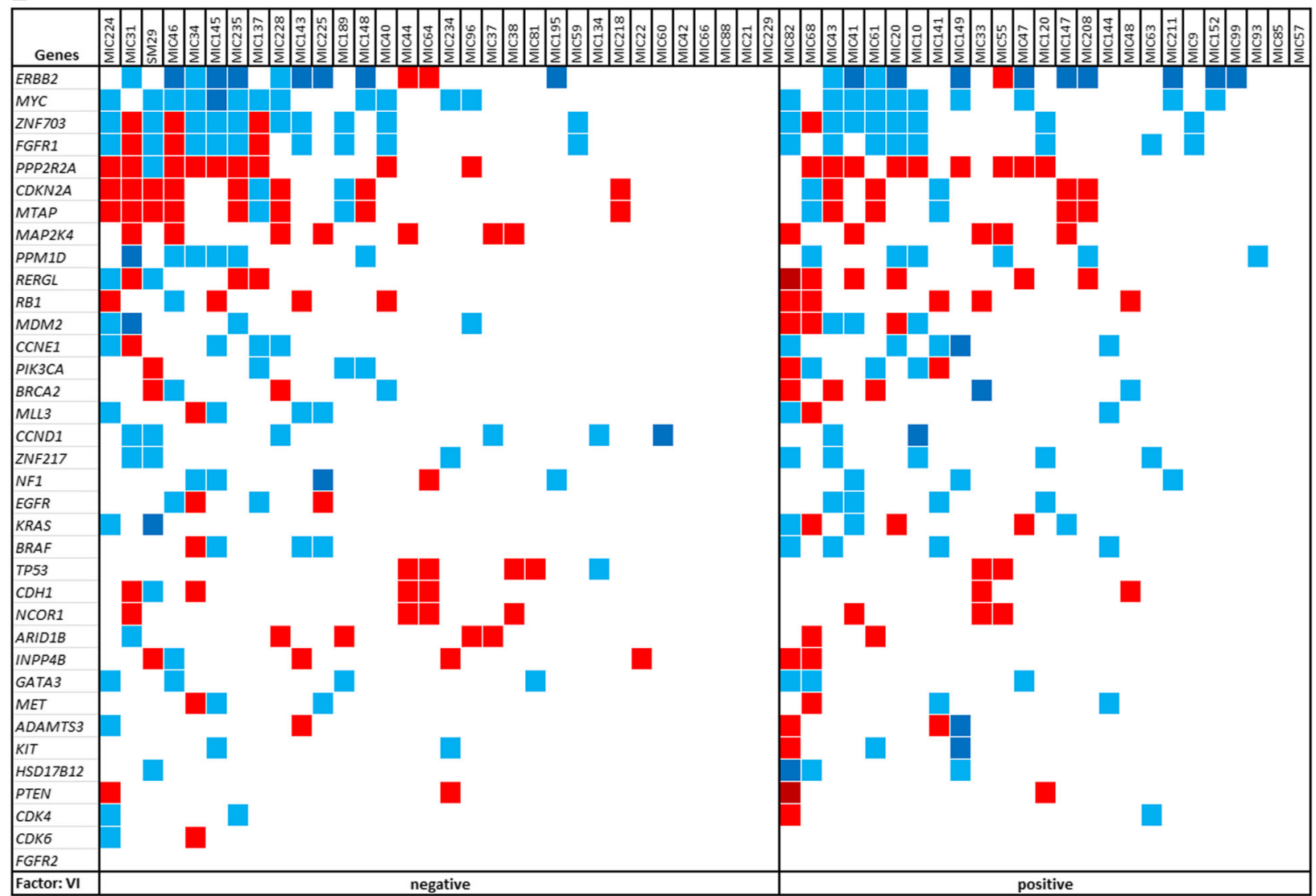


Fig. 4 Copy number changes of a panel of 36 genes in all 57 breast tumor samples grouped according to SBR grades or lymphovascular invasion status. The copy number status of 33 breast cancer driver genes and 3 genes (rows) identified in the present study (ADAMTS3, $H S D 17 B 12$, and RERGL) is depicted for each tumor sample (columns) by colored squares: gains and amplifications are shown in blue and dark blue, respectively; losses and homozygous losses are red and dark red, respectively. a Schematic view showing the pattern of copy number changes of the panel of 36 genes in breast tumor samples grouped according to histologic grade. b Schematic view showing the pattern of copy number changes of the panel of 36 genes in breast tumors grouped according to lymphovascular invasion status

particular augmentation of the number of genomic gains in histologic grade III breast tumors. Despite the fact that LVI is also associated with high-risk breast cancer, no differences in the total number of CNAs were detected in our study considering the LVI status. Taken together, our data corroborate previous studies showing an accumulation of genomic alterations in more aggressive breast tumors, although it also suggests that vascular invasion is a prognostic marker not related to increased genomic instability.

CNA pattern according to histological grade

Grade III tumors exhibited a wide range of genomic aberrations previously reported for this category $[11,12]$; the previously reported 19q12 amplification [17] was detected in only one grade III tumor, although gains affecting 19q12 were identified in additional nine grade III samples, which allowed us to narrow the critical region to a $\sim 537 \mathrm{~kb}$ segment. It is noteworthy that all grade III tumors carrying the $19 \mathrm{q} 12$ gain were found to be negative for estrogen receptor, a finding that corroborates the link with poor outcome [11,28].

Some regions statistically associated with grade III tumors in our study harbor genes either frequently amplified in
Table 4 Top differentially expressed genes (positive fold-change values indicating upregulation and negative fold-change values indicating donwregulation) identified between histologic grade III breast tumors

\begin{tabular}{|c|c|c|c|c|c|c|c|}
\hline \multicolumn{4}{|c|}{ Histologic grade III ${ }^{\mathrm{a}}$} & \multicolumn{4}{|c|}{ Lymphovascular invasion positive $\mathrm{e}^{\mathrm{b}}$} \\
\hline Gene & Cytoband & Fold-change & $p$ value & Gene & Cytoband & Fold-change & $p$ value \\
\hline$S 100 A 8$ & $1 \mathrm{q} 21.3$ & 22.0278 & 0.001 & C19orf33 & $19 \mathrm{q} 13.2$ & 4.4608 & 0.021 \\
\hline DEFB1 & $8 \mathrm{p} 23.1$ & 14.2762 & 0.001 & $L G A L S 7 B$ & $19 \mathrm{q} 13.2$ & 3.5713 & 0.007 \\
\hline$A D M$ & $11 \mathrm{p} 15.4$ & 7.0605 & 0.001 & $C P E$ & $4 q 32.3$ & 3.0436 & 0.011 \\
\hline$M M P 1$ & $11 \mathrm{q} 22.2$ & 6.7464 & 0.001 & $A G B L 2$ & $11 \mathrm{p} 11.2$ & 2.9353 & 0.028 \\
\hline MCM10 & $10 \mathrm{p} 13$ & 6.4085 & 0.001 & $A R S G$ & $17 \mathrm{q} 24.2$ & 2.7475 & 0.044 \\
\hline TMSB15A & $\mathrm{Xq} 22.1$ & 6.2266 & 0.001 & $U M O D$ & $16 \mathrm{p} 12.3$ & 2.6808 & 0.025 \\
\hline SOX11 & $2 \mathrm{p} 25.2$ & 5.5269 & 0.001 & C13orf31 & $13 q 14.11$ & 2.6631 & 0.026 \\
\hline$Y B X 2$ & $17 \mathrm{p} 13.1$ & 5.3408 & 0.001 & МYСВРАР & $17 q 21.33$ & 2.5776 & 0.032 \\
\hline KRT81 & $12 \mathrm{q} 13.13$ & 5.3214 & 0.001 & $C X X C 4$ & $4 q 24$ & 2.5767 & 0.044 \\
\hline$E 2 F 8$ & $11 \mathrm{p} 15.1$ & 5.2362 & 0.001 & $M E D 1$ & $17 \mathrm{q} 12$ & 2.5187 & 0.033 \\
\hline NANOS1 & 10q26.11 & 5.1092 & 0.001 & SHISA5 & $3 \mathrm{p} 21.31$ & 2.5084 & 0.002 \\
\hline$C D C 45 L$ & $22 \mathrm{q} 11.21$ & 5.0596 & 0.001 & GFRA1 & $10 \mathrm{q} 25.3$ & -4.4772 & 0.021 \\
\hline$G R P$ & $18 \mathrm{q} 21.32$ & -8.9074 & 0.001 & MFI2 & $3 q 29$ & -4.0174 & 0.029 \\
\hline$C Y P 4 X 1$ & $1 \mathrm{p} 33$ & -8.1935 & 0.001 & $T B X 21$ & $17 q 21.32$ & -3.8633 & 0.038 \\
\hline SUSD3 & $9 \mathrm{q} 22.31$ & -8.0443 & 0.001 & $K R T 15$ & $17 \mathrm{q} 21.2$ & -3.6634 & 0.016 \\
\hline$A B A T$ & $16 \mathrm{p} 13.2$ & -7.3311 & 0.001 & NFASC & $1 \mathrm{q} 32.1$ & -3.3951 & 0.022 \\
\hline$E V L$ & $14 \mathrm{q} 32.2$ & -6.9978 & 0.001 & FZD5 & $2 \mathrm{q} 33.3$ & -3.1834 & 0.008 \\
\hline KLHDC 9 & $1 \mathrm{q} 23.3$ & -6.9593 & 0.001 & $T C F 7 L 1$ & $2 \mathrm{p} 11.2$ & -3.0653 & 0.047 \\
\hline C6orf 211 & $6 \mathrm{q} 25.1$ & -6.9305 & 0.001 & $M Y B P C 2$ & $19 q 13.33$ & -2.8301 & 0.021 \\
\hline$N E F H$ & $22 \mathrm{q} 12.2$ & -6.3975 & 0.001 & $C R A B P 1$ & $15 \mathrm{q} 25.1$ & -2.7727 & 0.017 \\
\hline CX3CR1 & $3 \mathrm{p} 22.2$ & -5.3859 & 0.001 & $C I B 2$ & $15 \mathrm{q} 25.1$ & -2.5553 & 0.018 \\
\hline SMOC2 & $6 q 27$ & -5.3324 & 0.001 & $D U S P 3$ & $17 q 21.31$ & -2.5391 & 0.001 \\
\hline$B T G 2$ & $1 \mathrm{q} 32.1$ & -5.3206 & 0.001 & & & & \\
\hline FAM198B & $4 \mathrm{q} 32.1$ & -5.0859 & 0.001 & & & & \\
\hline$C C D C 74 B$ & $2 \mathrm{q} 21.1$ & -5.0592 & 0.001 & & & & \\
\hline
\end{tabular}

${ }^{\mathrm{a}}$ Histological grade III: $p$ value $<0.001$ and fold change of $|5|$

${ }^{\mathrm{b}}$ Lymphovascular invasion positive: $p$ value $<0.05$ and fold change of $|2.5|$ and histologic grade I+II breast tumors (left) and between breast tumors positive or negative for lymphovascular invasion (right)
Lymphovascular invasion positive ${ }^{\mathrm{b}}$ 


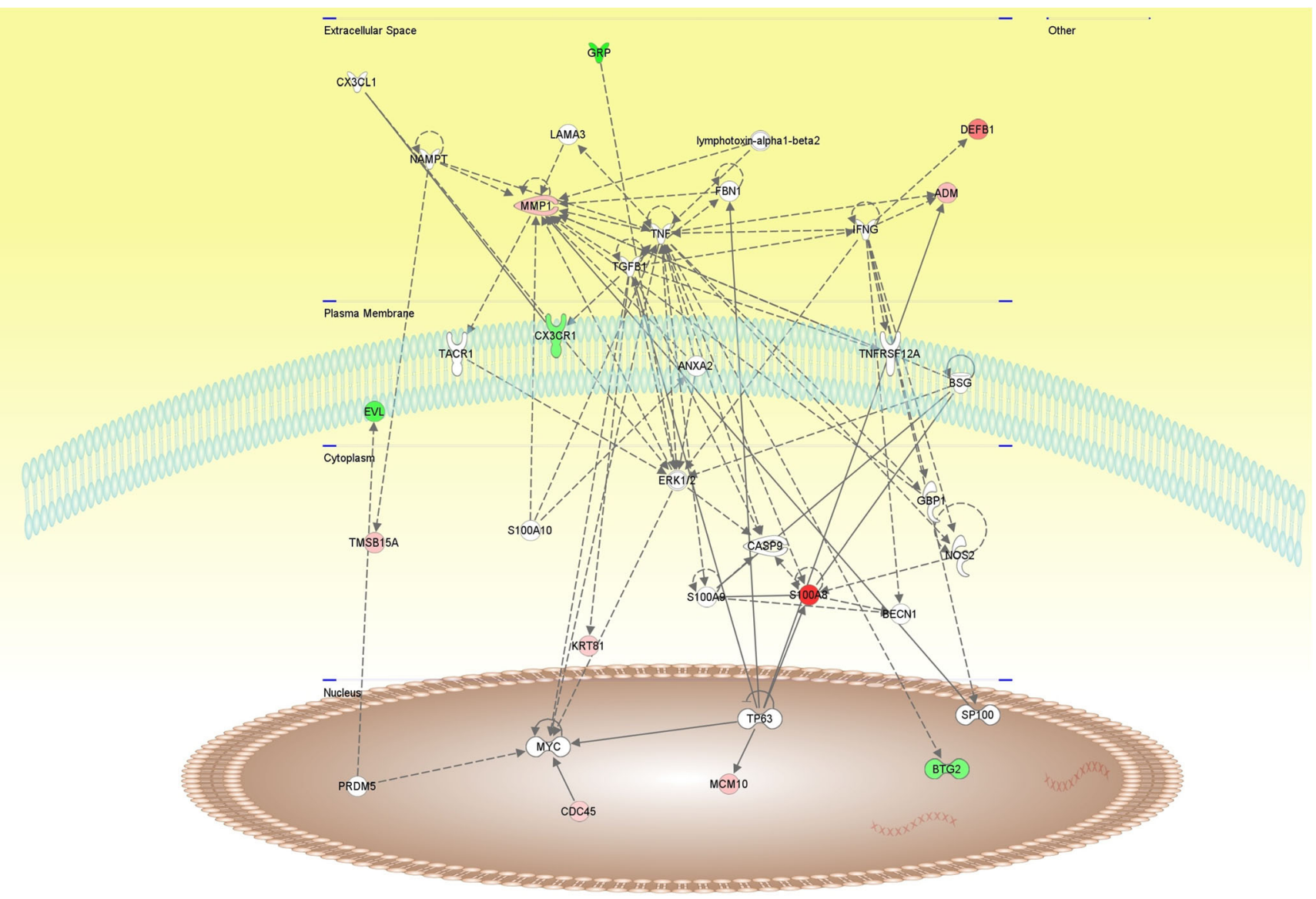

Fig. 5 Cellular diagram of the network created by the Ingenuity Pathway Analysis based on interactions of the set of differentially expressed genes detected in histologic grade III breast tumors compared to grade I and grade II tumors. Red and green nodes represent, respectively, upregulated or downregulated genes (the intensity of the colors indicating the degree of deregulation) in grade III breast tumors in comparison to grade I and II

aggressive breast cancer such as the oncogenes MYC (8q24) and CCNE1 (19q12) or already reported as deleted in breast tumors such as MTAP (9p21) [30]. The 8q22 gain is reportedly related to poor prognosis and chemoresistance possibly due to the activation of $M T D H$ [33], although the $8 \mathrm{q} 22$ segment here detected did not harbor this gene and included the cancer gene COX6C, which is involved in oxidative metabolism, upregulated in prostate tumors, and fusioned to HMGIC gene in uterine leiomyomas [34, 35]. Conversely, some of the detected regions in the present work are not strongly related to breast cancer; recurrent losses affecting 7p22 (segment encompassing, among others, the PMS2 gene) and 5q11-q13 (ERCC8 and XRCC4) could suggest the involvement of DNA repair pathways in cancer progression. The $5 \mathrm{q}$ loss also includes $F B X L 17$, a gene reported to be a biomarker for breast cancer resistance [36], and $M E F 2 C$, which was previously identified in association with breast cancer invasion [37]. The loss at $12 \mathrm{p} 12.3$ includes $L M O 3$, a key gene implicated in the onset and progression of several cancers [38]. tumors (Table 4); uncolored nodes represent genes automatically included in this network because they are biologically linked to the others based on scientific evidence. The functional categorization of this network was Cellular Movement, Hematological System Development and Function, Immune Cell Trafficking, with the $S 100 A 8$ gene playing a central role

Consistent with the literature $[12,18,39]$, the $16 \mathrm{p}$ gain was detected here preferentially in low-grade tumors $(33.3 \%$ of grade I samples and $52.9 \%$ of grade II samples), and all of them were estrogen-positive samples.

\section{CNA pattern according to LVI status}

Although the LVI-positive tumors were not associated with an increased genomic instability compared to LVI-negative tumors, they showed a few genomic alterations detected at a slightly higher frequency than the negative group, such as gains at $5 \mathrm{p}, 17 \mathrm{q} 12$ and 19 , and losses at $8 \mathrm{p}, 11 \mathrm{q}, 18 \mathrm{q}$, and 21. The most interesting alteration was an $11 \mathrm{q} 24.3$ loss harboring ARHGAP32, a gene earlier reported to be involved in fusion events in breast cancer cell lines and to participate in autophagy processes [40-43]. Additionally, the 16p gain was also preferentially associated with the absence of LVI ( $40 \%$ of LVI-negative tumors), which reinforces this CNA as a marker of good prognosis [12, 18, 39]. 
Table 5 Summary of the relevant genomic regions and genes revealed in this work in association either with histologic grade III or with lymphovascular invasion

\begin{tabular}{|c|c|c|}
\hline Relevant gene(s) & Chromosomal alteration & Clinical association \\
\hline$M Y C$ & $8 \mathrm{q} 24$ gain & Preferentially detected in grade III samples \\
\hline MTAP & $9 \mathrm{p} 21$ loss & Preferentially detected in grade III samples \\
\hline COX6C & $8 \mathrm{q} 22$ gain & Preferentially detected in grade III samples \\
\hline$P M S 2$ & $7 \mathrm{p} 22$ loss & Preferentially detected in grade III samples \\
\hline ERCC8, XRCC4, FBXL17, MEF2C & $5 \mathrm{q} 11 \mathrm{q} 13$ loss & Preferentially detected in grade III samples \\
\hline LMO3 & $12 \mathrm{p} 12.3$ loss & Preferentially detected in grade III samples \\
\hline $\begin{array}{l}\text { CCNE1, LOC284395, VSTM2B, POP4, } \\
\quad \text { PLEKHF1, C19orf } 12\end{array}$ & $\begin{array}{l}19 \mathrm{q} 12 \text { minimum common } \\
\text { region of gain }\end{array}$ & Exclusively detected in grade III negative for estrogen-receptor samples \\
\hline ADAMTS3 & 4q13.3 amplification & Detected in a grade III LVI-positive sample \\
\hline HSD $17 B 12$ & 11p11.2 amplification & Detected in a grade III LVI-positive sample \\
\hline RERGL, PIK3C2G & $\begin{array}{l}\text { 12p12.3 homozygous } \\
\text { deletion }\end{array}$ & Detected in a grade III LVI-positive sample \\
\hline ARHGAP32 & $11 \mathrm{q} 24.3$ loss & Preferentially detected in LVI-positive samples \\
\hline S100A8, MCM10 & - & $\begin{array}{l}\text { Concordant pattern of upregulated gene expression and copy number gains in } \\
\text { grade III samples }\end{array}$ \\
\hline GRP, CX3CR1, FAM198B & - & $\begin{array}{l}\text { Concordant pattern of downregulated gene expression and copy number losses } \\
\text { in grade III samples }\end{array}$ \\
\hline$U M O D, A R S G, M Y C B P A P, M E D 1$ & - & $\begin{array}{l}\text { Concordant pattern of upregulated gene expression and copy number gains/ } \\
\text { high gains in LVI-positive samples }\end{array}$ \\
\hline Several & 16p gain & $\begin{array}{l}\text { Preferentially detected in both low-grade and LVI-negative samples (exclu- } \\
\text { sively estrogen-receptor-positive tumors) }\end{array}$ \\
\hline
\end{tabular}

Copy number status of known driver genes and new genes proposed for breast cancer

Known breast cancer amplicons were detected as gains either exclusively $(19 q 12)$ or predominantly in grade III tumors [15, 44]. The 20q13.2 amplicon, previously associated with poor outcome [30, 44-47], was related in our study both to highgrade and LVI-positive tumors. We identified three new focal rearrangements in grade III/LVI-positive breast tumors: 4q13 and 11q11 amplifications (harboring the ADAMTS3 and the $H S D 17 B 12$ genes, respectively) and a homozygous deletion at 12 p12.3 (containing, among others, the RERGL gene). These highlighted regions because of the small size and the amplitude of the copy number changes indicate potential driver genes for breast cancer. The ADAMTS3 gene belongs to the ADAMTS metalloproteinase family that has been implicated in tumor progression [44-46]. Overexpression of HSD17B12 was recently associated with $C O X 2$ (1q31) overexpression in breast carcinomas [47], and in our cohort, HSD17B12 gains were detected in association with $C O X 2$ gains, which may indicate a new 1q31/11p11 co-amplification pattern in ERnegative high-grade breast tumors. However, functional studies are necessary to validate the biological relevance of the emphasized genes.

Additionally, we assembled a panel of genes exhibiting differences in the frequency of copy number changes between high-grade and low-grade breast tumors groups (see Table 5), including two of those genes here reported (RERGL and $H S D 17 B 12)$. Finally, the combination of frequencies of copy number changes of two genes was detected in LVI-positive breast cancer group: gains of ERBB2 and losses of RERGL.

\section{Gene expression profiling}

Concerning the gene expression pattern of grade III breast tumors, the $S 100 A 8$ gene, the top upregulated gene in grade III compared to low-grade tumors, appeared to be a central gene in the main regulatory network. This gene can act as a potent amplifier of inflammation in autoimmunity as well as of cancer development and metastasis [48-50]. S100A8 overexpression in high-grade breast tumors in comparison to lowgrade tumors has been previously reported [51] and associated with poor prognosis, poor tumor differentiation, LVI, and node metastasis when co-expressed with S100A9 [52]. Another promising candidate gene for breast cancer aggressiveness is $M M P 1$, which belongs to a matrix metalloproteinase family associated with cell growth, metastasis, and the progression of different neoplasias, including breast cancer [53-56]. A recent paper by our group disclosed another gene of the same family, $M M P 2$, as a key player in the progression of ductal carcinomas of the breast [57].

Some of the genes with the highest differential expression (fold change $>|5|$ for histological grade, fold change $>|3|$ for LVI) exhibited direct correlations between copy number 
changes and expression levels, such as gains affecting $S 100 \mathrm{~A} 8$ and MCM10, which suggests that expression levels could be driven by CNAs $[17,58,59]$. We also detected a downregulation pattern for $R E R G$, a gene from the family of the abovementioned deleted RERGL gene.

Regarding the LVI tumors, the most upregulated gene in the LVI-positive group compared to the negative group was C19orf33 which is also known as IMUP (immortalization upregulated protein), a gene previously shown to be overexpressed in lung, colon, and ovarian carcinoma cell lines $[60,61]$. Another remarkable upregulated gene was $L G A L S 7 B$, a basal cell marker which enhances metastasis to the lungs and bones in breast cancer [62]. Additionally, the upregulated MED1 gene, earlier reported in association with metastasis and therapy resistance in breast tumors [63], was uncovered as a relevant gene in a network enriched for genes in the categories of Cellular Growth and Proliferation and Hematological System Development and Function. A concordant pattern of association between CNAs and the expression profile was detected in our study for some genes already implicated in invasion and metastasis, such as gains and amplifications of MYCBPAP and MED1 [63, 64]. Furthermore, downregulated genes in tumors exhibiting LVI included $M F I 2$, a gene associated with breast cancer metastasis when downregulated [65].

\section{Conclusion}

Therefore, we could delineate a group of genomic alterations and relevant genes (see Table 5) that seems to be associated with high-grade breast cancer as well as with LVI. We recognize that histologic grade and LVI are easily evaluated in routine histological analysis, but CNA screening upon the diagnosis of low-grade breast tumors could assist in the identification of potentially more aggressive tumors requiring further investigation. Our study has shed some light on the molecular players involved in two highly relevant prognostic factors and may enable a better understanding of the mechanisms of breast cancer aggressiveness.

Acknowledgments This work was supported by the National Institute of Science and Technology in Oncogenomics (2008/57887-9), and FAPESP (2012/12139-5, 2012/21932-6, 2011/24007-9).

Conflicts of interest None.

Open AccessThis article is distributed under the terms of the Creative Commons Attribution License which permits any use, distribution, and reproduction in any medium, provided the original author(s) and the source are credited.

\section{References}

1. Kamangar F, Dores GM, Anderson WF. Patterns of cancer incidence, mortality, and prevalence across five continents: defining priorities to reduce cancer disparities in different geographic regions of the world. J Clin Oncol. 2006;24:2137-50.

2. Kothari MS, Rusby JE, Agusti AA, MacNeill FA. Sentinel lymph node biopsy after previous axillary surgery: a review. Eur J Surg Oncol. 2012;38:8-15.

3. McGuire WL. Prognostic factors for recurrence and survival in human breast cancer. Breast Cancer Res Treat. 1987;10:5-9.

4. Foster RS. The biologic and clinical significance of lymphatic metastases in breast cancer. Surg Oncol Clin N Am. 1996;5:79-104.

5. Schoppmann SF, Bayer G, Aumayr K, Taucher S, Geleff S, Rudas M, et al. Group ABaCCS: prognostic value of lymphangiogenesis and lymphovascular invasion in invasive breast cancer. Ann Surg. 2004;240:306-12.

6. Lee AH, Pinder SE, Macmillan RD, Mitchell M, Ellis IO, Elston CW, et al. Prognostic value of lymphovascular invasion in women with lymph node negative invasive breast carcinoma. Eur J Cancer. 2006;42:357-62.

7. Elston CW, Ellis IO. Pathological prognostic factors in breast cancer: I. The value of histological grade in breast cancer: experience from a large study with long-term follow-up. Histopathology. 1991;19:40310.

8. van't Veer LJ, Dai H, van de Vijver MJ, He YD, Hart AA, Mao M, et al. Gene expression profiling predicts clinical outcome of breast cancer. Nature. 2002;415:530-6.

9. van de Vijver MJ, He YD, van't Veer LJ, Dai H, Hart AA, Voskuil DW, et al. A gene-expression signature as a predictor of survival in breast cancer. N Engl J Med. 2002;347:1999-2009.

10. Walker LC, Harris GC, Wells JE, Robinson BA, Morris CM. Association of chromosome band 8q22 copy number gain with high grade invasive breast carcinomas by assessment of core needle biopsies. Genes Chromosom Cancer. 2008;47:405-17.

11. Natrajan R, Lambros MB, Rodríguez-Pinilla SM, Moreno-Bueno G, Tan DS, Marchió C, et al. Tiling path genomic profiling of grade 3 invasive ductal breast cancers. Clin Cancer Res. 2009;15:2711-22.

12. Bergamaschi A, Kim YH, Wang P, Sørlie T, Hernandez-Boussard T, Lonning PE, et al. Distinct patterns of DNA copy number alteration are associated with different clinicopathological features and geneexpression subtypes of breast cancer. Genes Chromosom Cancer. 2006;45:1033-40.

13. Bowcock AM. Invited review DNA copy number changes as diagnostic tools for lung cancer. Thorax. 2014;69:495-6.

14. Hirose Y, Sasaki H, Abe M, Hattori N, Adachi K, Nishiyama Y, et al. Subgrouping of gliomas on the basis of genetic profiles. Brain Tumor Pathol. 2013;30:203-8.

15. Ueno T, Emi M, Sato H, Ito N, Muta M, Kuroi K, et al. Genome-wide copy number analysis in primary breast cancer. Expert Opin Ther Targets. 2012;16 Suppl 1:S31-5.

16. Inaki K, Liu ET. Structural mutations in cancer: mechanistic and functional insights. Trends Genet. 2012;28:550-9.

17. Natrajan R, Mackay A, Wilkerson PM, Lambros MB, Wetterskog D, Arnedos M, et al. Functional characterization of the 19q12 amplicon in grade iii breast cancers. Breast Cancer Res. 2012;14:R53.

18. Kwei KA, Kung Y, Salari K, Holcomb IN, Pollack JR. Genomic instability in breast cancer: pathogenesis and clinical implications. Mol Oncol. 2010;4:255-66.

19. Wolff AC, Hammond ME, Schwartz JN, Hagerty KL, Allred DC, Cote RJ, et al. Oncology ASoC, Pathologists CoA: American Society of Clinical Oncology/College of American Pathologists guideline recommendations for human epidermal growth factor receptor 2 testing in breast cancer. J Clin Oncol. 2007;25:118-45. 
20. Hammond ME, Hayes DF, Dowsett M, Allred DC, Hagerty KL, Badve S, et al. American Society of Clinical Oncology/College of American Pathologists guideline recommendations for immunohistochemical testing of estrogen and progesterone receptors in breast cancer. J Clin Oncol. 2010;28:2784-95.

21. Campos AH, Silva AA, Mota LD, Olivieri ER, Prescinoti VC, Patrão $\mathrm{D}$, et al. The value of a tumor bank in the development of cancer research in Brazil: 13 years of experience at the a c Camargo hospital. Biopreserv Biobank. 2012;10:168-73.

22. Mueller O, Lightfoot S, Schroeder A (2004) RNA integrity number (RIN) - standardization of RNA quality control. BMC Mol Biol. 2006;317:3

23. Dokidis A, Delenstarr G (2005) Use of Agilent Feature Extraction Software (v8.1) - QC report to evaluate microarray performance. Agilent Technologies, Santa Clara.

24. Diskin SJ, Eck T, Greshock J, Mosse YP, Naylor T, Stoeckert CJ, et al. STAC: a method for testing the significance of DNA copy number aberrations across multiple array-CGH experiments. Genome Res. 2006;16:1149-58.

25. Livak KJ, Schmittgen TD. Analysis of relative gene expression data using real-time quantitative PCR and the $2(-$ delta delta $\mathrm{C}(\mathrm{T}))$ method. Methods. 2001;25:402-8.

26. Parker JS, Mullins M, Cheang MC, Leung S, Voduc D, Vickery T, et al. Supervised risk predictor of breast cancer based on intrinsic subtypes. J Clin Oncol. 2009;27:1160-7.

27. Carey L, Winer E, Viale G, Cameron D, Gianni L. Triple-negative breast cancer: disease entity or title of convenience? Nat Rev Clin Oncol. 2010;7:683-92.

28. Letessier A, Sircoulomb F, Ginestier C, Cervera N, Monville F, GelsiBoyer V, et al. Frequency, prognostic impact, and subtype association of $8 \mathrm{p} 12,8 \mathrm{q} 24,11 \mathrm{q} 13,12 \mathrm{p} 13,17 \mathrm{q} 12$, and $20 \mathrm{q} 13$ amplifications in breast cancers. BMC Cancer. 2006;6:245.

29. Network CGA. Comprehensive molecular portraits of human breast tumours. Nature. 2012;490:61-70.

30. Curtis C, Shah SP, Chin SF, Turashvili G, Rueda OM, Dunning MJ, et al. The genomic and transcriptomic architecture of 2,000 breast tumours reveals novel subgroups. Nature. 2012;486:346-52.

31. Stephens PJ, Tarpey PS, Davies H, Van Loo P, Greenman C, Wedge $\mathrm{DC}$, et al. The landscape of cancer genes and mutational processes in breast cancer. Nature. 2012;486:400-4

32. Spellman P, Gray J. A new treasure in the breast cancer gene hunt. Nat Med. 2011;17:422-3.

33. Hu G, Chong RA, Yang Q, Wei Y, Blanco MA, Li F, et al. MTDH activation by $8 \mathrm{q} 22$ genomic gain promotes chemoresistance and metastasis of poor-prognosis breast cancer. Cancer Cell. 2009;15:920 .

34. Kurose K, Mine N, Doi D, Ota Y, Yoneyama K, Konishi H, et al. Novel gene fusion of COX6C at 8q22-23 to HMGIC at 12q15 in a uterine leiomyoma. Genes Chromosom Cancer. 2000;27:303-7.

35. Wang FL, Wang Y, Wong WK, Liu Y, Addivinola FJ, Liang P, et al. Two differentially expressed genes in normal human prostate tissue and in carcinoma. Cancer Res. 1996;56:3634-7.

36. Xiao GG, Zhou BS, Somlo G, Portnow J, Juhasz A, Un F, et al. Identification of F-box/LLR-repeated protein 17 as potential useful biomarker for breast cancer therapy. Cancer Genomics Proteomics. 2008;5:151-60.

37. Schuetz CS, Bonin M, Clare SE, Nieselt K, Sotlar K, Walter M, et al. Progression-specific genes identified by expression profiling of matched ductal carcinomas in situ and invasive breast tumors, combining laser capture microdissection and oligonucleotide microarray analysis. Cancer Res. 2006;66:5278-86.

38. Matthews JM, Lester K, Joseph S, Curtis DJ. LIM-domain-only proteins in cancer. Nat Rev Cancer. 2013;13:111-22.

39. Jönsson G, Staaf J, Vallon-Christersson J, Ringnér M, Holm K, Hegardt $\mathrm{C}$, et al. Genomic subtypes of breast cancer identified by array-comparative genomic hybridization display distinct molecular and clinical characteristics. Breast Cancer Res. 2010;12:R42.

40. Schulte I, Batty EM, Pole JC, Blood KA, Mo S, Cooke SL, et al. Structural analysis of the genome of breast cancer cell line ZR-75-30 identifies twelve expressed fusion genes. BMC Genomics. 2012;13: 719 .

41. Kaminsky EB, Kaul V, Paschall J, Church DM, Bunke B, Kunig D, et al. An evidence-based approach to establish the functional and clinical significance of copy number variants in intellectual and developmental disabilities. Genet Med. 2011;13:777-84.

42. Miller DT, Adam MP, Aradhya S, Biesecker LG, Brothman AR, Carter NP, et al. Consensus statement: chromosomal microarray is a first-tier clinical diagnostic test for individuals with developmental disabilities or congenital anomalies. Am J Hum Genet. 2010;86:74964

43. Okabe T, Nakamura T, Nishimura YN, Kohu K, Ohwada S, Morishita Y, et al. RICS, a novel GTPase-activating protein for $\mathrm{Cdc} 42$ and Rac1, is involved in the beta-catenin- $\mathrm{N}$-cadherin and $\mathrm{N}$ methyl-D-aspartate receptor signaling. J Biol Chem. 2003;278:9920

44. Fernandes RJ, Hirohata S, Engle JM, Colige A, Cohn DH, Eyre DR, et al. Procollagen II amino propeptide processing by ADAMTS-3. Insights on dermatosparaxis. J Biol Chem. 2001;276:31502-9.

45. Porter S, Scott SD, Sassoon EM, Williams MR, Jones JL, Girling $\mathrm{AC}$, et al. Dysregulated expression of adamalysin-thrombospondin genes in human breast carcinoma. Clin Cancer Res. 2004;10:2429 40

46. Molokwu CN, Adeniji OO, Chandrasekharan S, Hamdy FC, Buttle DJ. Androgen regulates ADAMTS15 gene expression in prostate cancer cells. Cancer Investig. 2010;28:698-710.

47. Visus C, Ito D, Dhir R, Szczepanski MJ, Chang YJ, Latimer JJ, et al. Identification of hydroxysteroid (17 $\beta$ ) dehydrogenase type 12 (HSD17b12) as a CD8+ T-cell-defined human tumor antigen of human carcinomas. Cancer Immunol Immunother. 2011;60:919-29.

48. Srikrishna G. S100a8 and S100a9: new insights into their roles in malignancy. J Innate Immunol. 2012;4:31-40.

49. Berthier S, Nguyen MV, Baillet A, Hograindleur MA, Paclet MH, Polack B, et al. Molecular interface of S100a8 with cytochrome b558 and NADPH oxidase activation. PLoS One. 2012;7:e40277.

50. Yanamandra K, Alexeyev O, Zamotin V, Srivastava V, Shchukarev A, Brorsson AC, et al. Amyloid formation by the pro-inflammatory S100a8/A9 proteins in the ageing prostate. PLoS One. 2009;4:e5562.

51. McKiernan E, McDermott EW, Evoy D, Crown J, Duffy MJ. The role of S100 genes in breast cancer progression. Tumour Biol. 2011;32:441-50.

52. Arai K, Takano S, Teratani T, Ito Y, Yamada T, Nozawa R. S100a8 and S100a9 overexpression is associated with poor pathological parameters in invasive ductal carcinoma of the breast. Curr Cancer Drug Targets. 2008;8:243-52.

53. Pulukuri SM, Rao JS. Matrix metalloproteinase-1 promotes prostate tumor growth and metastasis. Int J Oncol. 2008;32:757-65.

54. Schütz A, Schneidenbach D, Aust G, Tannapfel A, Steinert M, Wittekind C. Differential expression and activity status of MMP-1, MMP-2 and MMP-9 in tumor and stromal cells of squamous cell carcinomas of the lung. Tumour Biol. 2002;23. 179-84.

55. Slattery ML, John E, Torres-Mejia G, Stern M, Lundgreen A, Hines $\mathrm{L}$, et al. Matrix metalloproteinase genes are associated with breast cancer risk and survival: the breast cancer health disparities study. PLoS One. 2013;8:e63165.

56. Fanjul-Fernández M, Folgueras AR, Fueyo A, Balbín M, Suárez MF, Fernández-García MS, et al. Matrix metalloproteinase Mmp-1a is dispensable for normal growth and fertility in mice and promotes lung cancer progression by modulating inflammatory responses. J Biol Chem. 2013;288:14647-56. 
57. Carraro DM, Elias EV, Andrade VP. Ductal carcinoma in situ of the breast: morphological and molecular features implicated in progression. Biosci Rep. 2013;34(1):e00090.

58. Rachidi SM, Qin T, Sun S, Zheng WJ, Li Z. Molecular profiling of multiple human cancers defines an inflammatory cancer-associated molecular pattern and uncovers KPNA2 as a uniform poor prognostic cancer marker. PLoS One. 2013;8:e57911.

59. Batra R, Harder N, Gogolin S, Diessl N, Soons Z, Jäger-Schmidt C, et al. Time-lapse imaging of neuroblastoma cells to determine cell fate upon gene knockdown. PLoS One. 2012;7:e50988.

60. Kim JK, Ryll R, Ishizuka Y, Kato S. Identification of cDNAs encoding two novel nuclear proteins, IMUP-1 and IMUP-2, upregulated in SV40immortalized human fibroblasts. Gene. 2000;257:327-34.

61. Ryoo ZY, Jung BK, Lee SR, Kim MO, Kim SH, Kim HJ, et al. Neoplastic transformation and tumorigenesis associated with overexpression of IMUP-1 and IMUP-2 genes in cultured NIH/3T3 mouse fibroblasts. Biochem Biophys Res Commun. 2006;349:995-1002.
62. Demers M, Rose AA, Grosset AA, Biron-Pain K, Gaboury L, Siegel $\mathrm{PM}$, et al. Overexpression of galectin-7, a myoepithelial cell marker, enhances spontaneous metastasis of breast cancer cells. Am J Pathol. 2010;176:3023-31.

63. Moelans CB, van der Groep P, Hoefnagel LD, van de Vijver MJ, Wesseling P, Wesseling J, et al. Genomic evolution from primary breast carcinoma to distant metastasis: few copy number changes of breast cancer related genes. Cancer Lett. 2013;344(1):138-46.

64. Sabe H, Hashimoto S, Morishige M, Ogawa E, Hashimoto A, Nam JM, et al. The EGFR-GEP100-Arf6-AMAP1 signaling pathway specific to breast cancer invasion and metastasis. Traffic. 2009;10:982-93.

65. Bemmo A, Dias C, Rose AA, Russo C, Siegel P, Majewski J. Exonlevel transcriptome profiling in murine breast cancer reveals splicing changes specific to tumors with different metastatic abilities. PLoS One. 2010;5:e11981. 